\title{
E-Commerce Framework for Strategic Marketing of Udupi Jasmine
}

\author{
Darryl Jeethesh D'souza' ${ }^{1}$ Harisha G. Joshi² \\ ${ }^{1}$ School of Information Sciences, Manipal Academy of Higher Education, India \\ ${ }^{2}$ School of Management, Manipal Academy of Higher Education, India
}

\begin{abstract}
Udupi jasmine cultivation plays an important role towards economic and social growth for the jasmine growing community-based enterprise of coastal Karnataka, India. It helps in promoting rural livelihoods, food security and poverty reduction. Due to the significant socio-economic impact of jasmine cultivation, the promotion and marketing of jasmine is inevitable for the sustenance of this community-based enterprise This study aims in developing an e-commerce framework for strategic marketing and promotion of Udupi jasmine. Study found that the benefits of e-business was nowhere applied in the existing system. As Udupi jasmine is a unique crop with a geographical indication tag (GI), regular agricultural framework cannot not be directly used. The research intents to persuade utilization of customized e-commerce framework for jasmine considering the existing crude system. This will reinforce the socio-economic growth of this communitybased enterprise as there will be a well-organized circulation of agricultural products on a larger scale.
\end{abstract}

\section{Keywords}

Udupi jasmine, e-commerce, e-business, community-based enterprise, socio-economic, policy making, e-agriculture, ICT.

D'souza, D. J. and Joshi, H. G. (2019) "E-Commerce Framework for Strategic Marketing of Udupi Jasmine", AGRIS on-line Papers in Economics and Informatics, Vol. 11, No. 1, pp. 17-26. ISSN 1804-1930. DOI 10.7160/aol.2019.110102.

\section{Introduction}

Jasmine is one of the oldest flowers grown for their aromatic scent. It is widely used in southern India for various decorative purposes and for personal use. Jasmine is also used in production of perfumes and cosmetics. Although there are more than 50 types of jasmine species grown in India, out of which only three species are used for commercial purposes. Udupi Jasmine belongs to one of these species of Jasminum Sambac-1 species of jasmine (Ashok and Sarma, 2016). Udupi Jasmine has also been accorded with a geographical indication tag in 2008. Majority of the Udupi jasmine is grown in the Shankarapura region of Udupi district of coastal Karnataka, India. Udupi jasmine flower growing community of coastal Karnataka have maintained a community-based enterprise for more than 85 years. Many of the farmers of this region depend directly on cultivation of Udupi jasmine for their livelihood (Krishnamurthy et al., 1995). By the rule of thumb this communitybased enterprise has developed a working system of pricing, supply and distribution. Through mutual trust and cooperation, this community has kept poverty away for manny generations. Jasmine cultivation has a significant socio-economic impact on the cultivators. Although the cultivators have other sources of income, jasmine cultivation is the major source of their economy.

E-agriculture is a relatively recent term in the field of agriculture and rural development practices. Food and agriculture organization of the United Nations describes e-agriculture as an emerging field through improved information and communication processes, focuses on the enhancement of agricultural and rural development. E-agriculture to be more specific comprises of the approach, then designing, development based on the design, assessment and application of groundbreaking ways of using information and communication technologies (ICT) in the rural area, with the focus being agriculture.

Using internet to market products and services, buying and selling of goods and services, information exchange, creating and maintaining relationships over internet can be referred to as e-commerce which is one of the aspects of e-agriculture (Fruhling and Digman, 2000). E-commerce is believed to have the potential to increase profitability in agricultural 
markets by increasing sales and decreasing search and transactions costs. E-commerce markets tend to attract more customers as they are likely to be more transparent and competitive than physical markets, hence increase in demand (Montealegre et al., 2007). Agricultural e-commerce is to introduce e-strategy to improve the interaction and trading activities between participants in the agricultural sector and changing the configuration and relationships at various stages in linkages of the food supply chain. There has been much evidence that e-commerce offers an important opportunity for cost reduction and demand enhancement (Leroux et al., 2001).

Small stake holders often find it difficult to take advantage of market opportunities in developing countries due to the widespread irregularities of markets such as discontinuity of information on modern technologies and price, disconnection with the established market actors and constrains in credit process (Markelova et al., 2009).

One of the key aspects for any ICT project to succeed is the delivery of information to the key stake holders involved. The important factor in the success of a project depends on the way ICT projects apply, access, deliver and assess the content which in turn increases possibility of farmers using the ICT project. Generally, the critical factors in the success of a project is to understand the information needs of a farmer. Customization and localization of content to the farmers condition effects its relevance. (Glendenning and Ficarelli, 2012).

Local content is generally defined as content that is intended for a specific local audience, as defined by geographic location, language, culture and content that is socially, culturally, economically and politically relevant to a given society (Glendenning and Ficarelli, 2012). Thus, local content is the expression of a community's knowledge. Localization can be improved with the direct involvement of the users by personal interviews that involves question and answers. The sources that provide the content are generally the local experts and establishments who have expert local knowledge.

Manny of the ICT projects are not always relevant to local context and needs, because of a disconnect between the project and its end users (Ballantyne, 2002). Without the necessary knowledge of the working of the existing system and the necessities of framing community, often projects push content to people. In agriculture, information generation needs to be a two-way process, with research at the farm level so that contextually appropriate content can be generated (Chapman and Slaymaker, 2002). With a two way process farmers can generally share their experiences and best agricultural practices which can be incorporated to the program as farmer knowledge base (Silva, 2008). Content can then be contextualized by the ICT project based on the communities information needs. Multiple interactions with the community will insure the trust of the establishment, better understanding of the demands of local communities, hence providing insights to the needs of the community that the ICT platform will serve. Clear understanding of the demands of the communities requires competency in analysis of the needs, which involves the process based on actual dialogues with the members of the community, which then requires the empowerment and organization of the community. Thus, this complication will often hinder the ICT projects from serving the deprived groups within the community. (Chapman and Slaymaker, 2002).

Hence determining the community's needs along with the critical understanding of the existing system proves to be a major success factor for an ICT project. As localization is critical factor for an ICT project to succeed, this framework is designed based on the study conducted and inferences gained from the working of this community-based enterprise.

Introducing e-commerce to market Udupi jasmine has a number of benifits:

- Providing structure to a fragmented agricultural market. The Udupi jasmine market is large, dispersed market. E-Commerce may assist in providing answers by assimilating individual actors to improve the structure of the organization. Through the internet many aspects of business can be managed.

- With a limited investment the e-commerce can improve the market reach. Irrespective of the geographic location ICT technologies provides with the chance with a little investment in infrastructure to link various actors in the farming chain. By reducing the obstacles of geographic locations of market reach such as time and distance it increases the market reach through online transactions.

- Price transparency and price stability will improve online. Online access to product and price information will allow comparison 
of products and increase price transparency. Fluctuations in price likely to diminish because of increase in competition. Also, the demand will increase as the accessibility is increased to a larger population and hence stability in price.

- Accessibility will be key to acceptance. Adoption of an interment technology depends on the accessibility along with the benefits it offers. Udupi jasmine has got a significant socio-economic impact on the communitybased enterprise. The community-based enterprise has an unstructured system. Thus, e-commerce will assist to extend the reach of Udupi jasmine to a larger market.

- Better information exchange. Information exchange can help reduce the gap between consumers and cultivators.

- Formation of an alternative market structure. It will help in decreasing rural isolation and increasing market transparency.

- Enhance farming techniques and best practices. Timely interventions can help improve farming techniques and adopt best practices in agriculture and in policy making.

E-commerce theories in agriculture has different approaches. The term "Business to Business" (B2B) implies similarities or equal partners in trade. By contrast "Business to Consumer" (B2C) suggests a difference between the two parties. The framework attempts to integrate both these business models. The framework focuses on the functions provided by the ecommerce system and does not consider the infrastructure support for e-commerce. Development of the framework also takes inputs from different architectures that will assist this framework in conducting smooth commerce over the internet. The proposed framework intends to assist in improving the socio-economic status of the cultivators. The research gives priority to the existing system so that it can better integrate with the proposed system. The framework is designed exclusively for Udupi jasmine as it will provide a structure to an unstructured system.

\section{Materials and methods}

Udupi Jasmine is grown in specific regions of Shirva, Shankarapura, Belle (Moodubelle and Padubelle) of Udupi district, in coastal Karnataka, India. Delivery of information to the key stake holders involved is critical for an e-commerce project. To deliver relevant information to the stake holders understanding of the existing system with respect to the product is important. Usage of Udupi jasmine is very localized and mostly people who are acquainted with it engage in its business. In terms of market, consumers who are familiar and revere the crop are the ones who buy it. Thus, in development of the framework the following aspects are considered.

1. Recognize various actors involved in the system and how each one of them can contribute to the system.

2. Price determination and the variables that influence it.

3. Consumer needs.

4. Discerning some of the existing e-commerce frameworks.

Recognize various actors involved in the system and how each one of them can contribute to the system.

To understand the working of this communitybased enterprise, personal interviews were conducted with the various correspondents. The correspondents were jasmine growers, agents and traders. Snowballing technique was used in the selection of candidates. The process of jasmine collection by growers starts early in the morning and is finished by $10 \mathrm{am}$. Jasmine buds are not directly sold to the consumer, instead they are tied together to a 6-inch chain approximately and then sold. These bundles of tied buds are then collected by agents. Each household is connected to one among 150 agents who operate in the respective area.

Responsibility of the agent is to collect the buds from the household and then arranging them for commercial units comprising of 800 - 805 buds each. Then they are formed into four bundles for which price is fixed by traders each day. As not all households will be able to produce a unit with desired number of buds, the agents form these units with whatever buds they have collected from multiple households. Each agent is connected to multiple households from whom they collect these buds. During the collection process the grower informs the agent of the number of buds they have given, and the agent maintains a record (hard copy) about information of each farmer and price to be given for that day. Growers are paid on weekly basis by the agents for the collected produce.

The agents then supply these commercial units, to a designated trader located in Shankarapura. There are six traders in total to whom all 
the agents supply. The traders sell the collected units to wholesalers located outside the region. These units reach wholesalers as far as Mumbai and Dubai. The traders keep track of the units received from agents and appropriate payments are made to them on weekly basis.

Price determination and the variables that influence it

Determination of price per unit is done by the traders. The six traders come together to determine the price for a jasmine unit based on the requirements for that day. Based on the demand from their wholesalers, one of the 6 traders establish a price $X$ for that day. If the price $X$ is not acceptable by the wholesalers of other 5 traders, they decrease their demand. So, the remaining 5 traders are left with additional supply. The price $\mathrm{X}$ will be agreed upon by the other 5 traders only if the trader who quoted price $\mathrm{X}$ agrees to buy the additional supply. Thus, the traders engage in negotiations on price $X$ and will reach on a consensus in establishing price of jasmine for that day. The wholesalers purchase decision depends on the overall market demand. For a country routed deeply in religious traditions, auspicious days based on religious calendars influences demand. Jasmine cultivation as a major impact on the socio-economic conditions of the growers. It is critical to understand the variations in the price of Udupi jasmine as steps can be taken to stabilize it if variations are evident. The information collected on price will also be useful in generating trends and future price predictions, which will enhance the user experience. To understand the price variations of Udupi jasmine, price per day was collected from the year 2010 to 2016 .

\section{Consumer needs}

Udupi jasmine is coveted for its exquisite scent. It is a favored flower in religious ceremonies, formal events and for personal use. So, during festive seasons and functions at home the demand shoots up. India is a very traditional country. The people of coastal Karnataka generally keep functions on auspicious days based on religious calendars. Hence auspicious days based on religious calendars too has an adverse effect on demand, hence the price. Consumers who prefer Udupi jasmine for their daily personal use generally buy it from flower markets, but due to the busy life style most of them refrain from going to markets.

Discerning some of the existing e-commerce frameworks

National Agriculture Market (NAM) constitutes a classic example of e-commerce in the realm of agricultural marketing in India. It is a trading portal to create a unified national market for agricultural commodities by networking the existing Agricultural Produce Market Committee (APMC) mandis. NAM works in a B2B setting. APMC related information and services are provided to the user through a single window of NAM. Services such as trade offers to buy and sell, arrivals of commodity and prices, facility to respond to trade offers etc. Online market helps in reducing the information asymmetry and transaction costs, while mandis are used for the flow of materials.

In providing a comparative study of agriculture e-commerce business model between India and China, (Dong, 2016) argues that Indian agricultural e-commerce focuses one solving the poverty of farmers and it primary emphasis is given to reduce the farmer's cost involved in production and purchase. Whereas China's agricultural e-commerce focusses on improving the income of farmers. Thus, focus on improving the farmers income should be a priority in agricultural e-commerce framework as it effects the socio-economic status of a farmer.

While comparing the path of agricultural e-commerce between India and china (Dong, 2016), finds a number of differences in the important factors such as commodity circulation, information flow, capital flow, logistics, personnel flow and credit flow that affect the agricultural e-commerce.

In terms of listing four e-commerce systems functionalities: auctions, storefronts, enterprise portals and e-procurement (Turban et al., 2002) provide some direction for a functional model of e-commerce.

While comparing four architectures of e-commerce systems (Treese and Stewart, 2002) provides explanation of functional characteristics and reviews on each of the four systems. The four architectures compared are:

1. Open Buying on the Internet (OBI) architecture: The OBI group proposed this standard architecture for B2B e-commerce. It comprises functions for the purchasing organization to pick a supplier, surf the supplier's catalog and then an option to place an order. Other functionalities include options for confirming an order by the purchasing organization, authorization of an external payment authority 
for electronic payment and fulfillment of an order.

2. Merchant server architecture: This architecture provides functionalities for presentation of product, options to use information on products from an electronic catalog and entry of an order.

3. Open Market commerce architecture: Open Market developed this architecture that has options such as presentation of a product, usage of product information from an electronic catalog, electronic payment, fulfillment of an order, order entry and providing customer service.

4. Secure Electronic Transaction (SET): This architecture focuses on electronic payment function. SET architecture adds an electronic payment functionality to the merchant server model.

\section{Results and discussion}

\section{Price analysis of Udupi jasmine}

Graph 1 shows the average jasmine price received by the farmers form 2010-16. It is evident from graph 1 that the price is not stable. It is found that the factors effecting the price are festivals, functions, events and weather. Also, the production too plays as a key factor in the variation of jasmine price. Whenever there are festivals and special occasions there is a sharp rise in the price. During the months of October to January the prices remain high since there are several festivals and special occasions during this time. The production of jasmine flower too is moderate during these seasons.
From February to September the prices fluctuate and is generally low since the production is more, but demand is not constant. As there are no major festivals during these seasons there is no sharp increase in demand. Hence during these seasons if the demand can be increased price stability can be maintained. In the coastal region of Karnataka, India women generally decorate their hair with jasmine on daily basis throughout the year. E-commerce will open market to a wider range of audience across geographical locations and provide buying options for customers who use jasmine on daily basis. This will help to boost the demand factor and hence stability in price. Price analysis can also be used for future price predictions which will be valuable for farmers.

E-commerce Framework to market Udupi jasmine

The proposed e-commerce framework consists of the following interrelated functions:

E-commerce website, B2B Trading Platform, B2C Costumer Platform, Product Information, Electronic shopping cart, Support, Payment Gateway, Stock Management, Supply Chain Management, Information Exchange, Quantity Analyzer, Price Analyzer, SMS module, Mobile application for agents, Database, Data analysis. Interaction between the various functions are shown in Figure 1. Each function is dependent on each other to perform various activities that will assist in performing commerce over the internet.

\section{E-commerce website:}

Provides an online portal that will facilitate online transactions of goods and services through

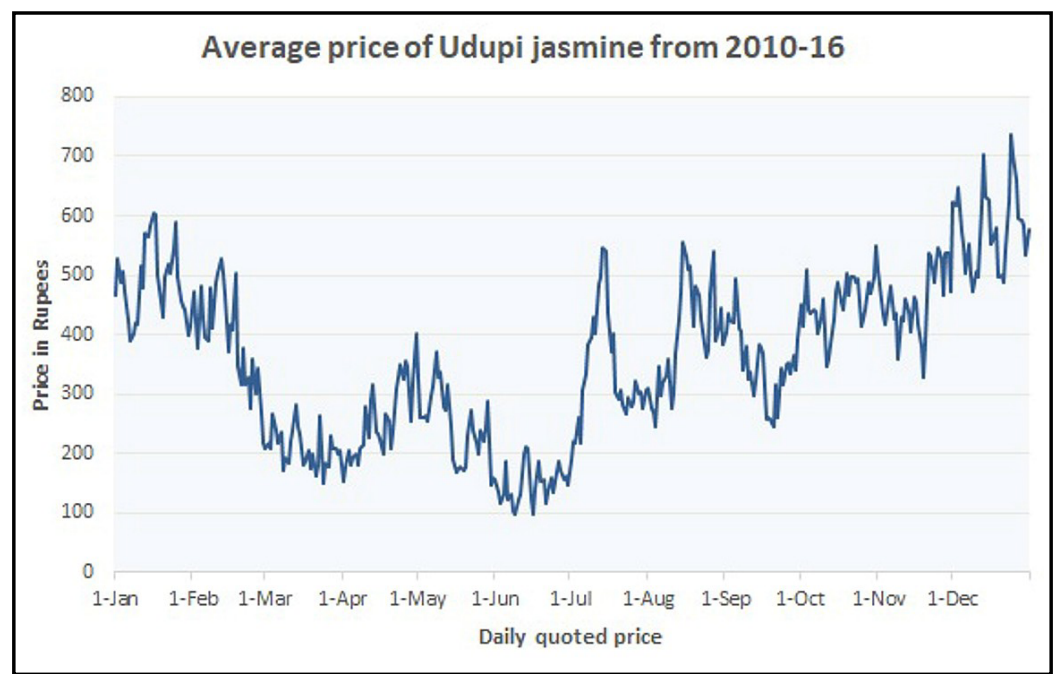

Source: own research and processing

Graph 1: Jasmine price variation from the year 2010-16. 


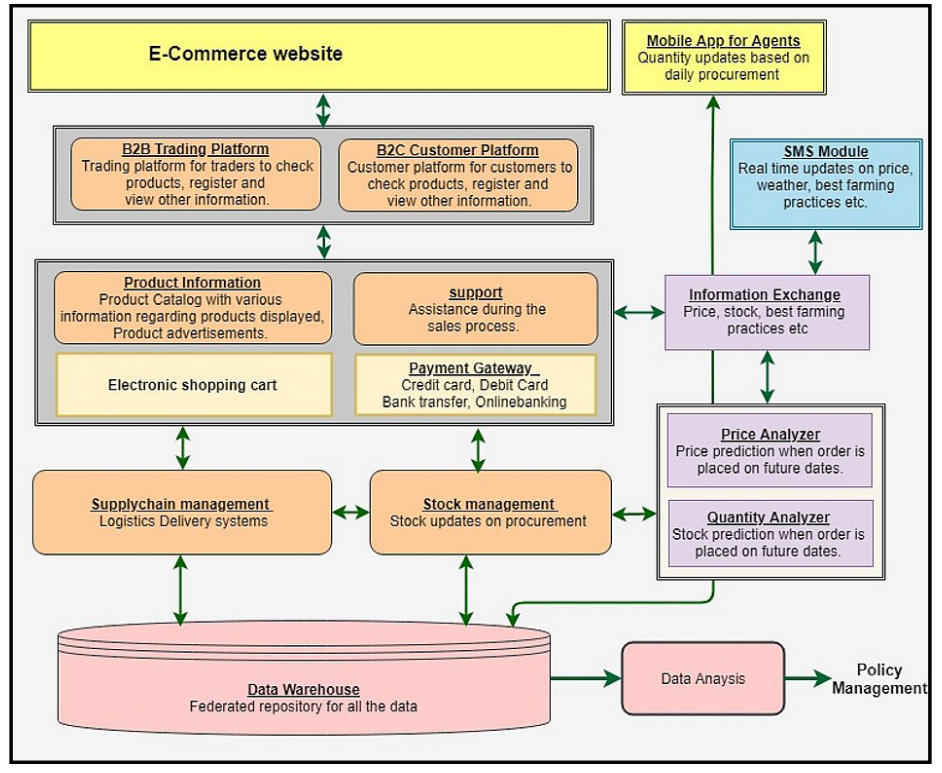

Source: own research and processing

Figure 1: E-commerce framework for Udupi Jasmine.

means of the transfer of information and funds over the Internet. Execution of any transactions related to buying and selling can be done online with the help of a website. The website interacts with the other components in the framework to produce the desired results based on customer interaction. Basically, it provides a front end for $\mathrm{B} 2 \mathrm{~B}$ and $\mathrm{B} 2 \mathrm{C}$ transactions between various actors involved.

\section{B2B trading platform:}

It provides a platform that will enable traders to conduct businesses. The will help eliminate business complexity and offers buyers numerous possibilities. It also helps in making trade easy without any geographical boundaries. It will provide features such as check products, register, shopping cart, price trends and payment gateway system.

\section{B2C Costumer Platform:}

B2C customer platform provides options for customers to buy products. It will provide features such as check products, register, shopping cart, price trends and other information. They will be also provided with a safe and secure payment gateway system to purchase the product once selected.

\section{Product Information:}

The product information function provides information about the crop. This function is included as the framework can be extended to other flowers or agricultural products as well.

The information can include:

- Crop descriptions.

- Interesting information about the crop that will help in promotion.

- Product views like photographs.

Additional features such as product search, selection of language and user preference customization.

\section{Electronic shopping cart:}

Electronic shopping cart provides an interface for users to place items in a "shopping basket" so that the products included can be remembered for a predetermined time. Shopping cart will include features such as quantity and matching links to the items. Once a customer inputs the shipping address, taxes and shipping costs can also be matched from within the shopping cart. It provides important information, which is often transparent to the customer including a cart number to track the order.

\section{Support:}

Assistance is provided to the user before and after the product has been received. It aids users with questions or problems related to the purchasing process. This assistance may be needed before, during or after a purchase. Assistance can also be provided during the entry of the product, payment related issues, tracking of order, exchange and return etc. 


\section{Payment Gateway:}

The payment gateway function provides the user options to pay for the order and thus complete the transaction. Payment options may include debit card, COD, credit card or any other electronic funds transfer method. With the national government starting several money transfer applications, transfer of payments has become much simpler even in rural India. Unified Payments Interface (UPI) can be also integrated for payments.

\section{Stock Management:}

Stock management function is useful to keep track of the stock available and the stock to be procured. Also, it keeps track of the changes made as per customer transactions.

\section{Supply Chain Management:}

The Supply Chain Management function is used in delivering the product to the customer. From the time order is placed by the costumer till the order is delivered the complete track of the process is taken care by this function. This also helps in updating the stock management function.

\section{Information Exchange:}

Information dissemination plays a major role in e-commerce. Information can be on price, products, trends etc. This information will influence the decision making of customers while buying products. This function thus provides various aspects related to information which is a major aspect in e-commerce. Information exchange function will gain inputs from price analyzer and quantity analyzer in providing information to the user such as price trends, availability of stock etc.

\section{Quantity Analyzer:}

This function helps in predicting the future stock. This is especially useful for Udupi jasmine as it is difficult to predict future stock. Udupi jasmine production is highly unpredictable. So, this function provides an estimation of future stock based on previous stock data, thus providing valuable information to the user on the availability of the product on a specified date.

\section{Price Analyzer:}

This function helps in predicting the future price of crops. Jasmine price is unstable. Jasmine prices vary daily as per production and demand. This function provides approximate future price based on previous information on price. It will also provide trends based on week, months and years. Thus, users will be provided information on the future prices which will enhance user buying experience.

\section{SMS Module:}

SMS module is an GSM based module which is intended to help customers and famers alike, who are not tech savvy and places with the lack of internet services. SMS module will provide users with information such as price, price trends etc. SMS module plays an important role in providing information to the grower. Crop price information which is critical for growers can be given via SMS, as they generally call the traders for price on daily basis. Also, timely information can be provided to growers on information on fertilizers, weather and best agricultural practices etc. This helps in providing effective information dissemination.

\section{Mobile application for agents:}

Agents play an important role in jasmine enterprise. They not only take care of the logistical part of jasmine collection and packing, they also collect valuable information on farmers and their daily agricultural output. Although data on quantity is taken on daily basis, information is not stored for long time. The existing data is in paper format.

A mobile app can be provided to the agents to automate the existing process. Agents can provide data about details of the grower and then update the daily agricultural outputs of Jasmine growers. For an e-commerce model to work for jasmine there should be multiple sources from where product can be procured. Information on agents and their daily procurement details will help in the efficiency of the e-commerce model. It will help in procuring jasmine based on orders.

At present there is no database on information of Udupi jasmine growers and their agricultural output. The mobile app will assist in maintaining this data as:

- The agents generally have grower information and collect data about quantity on daily basis.

- Most of the agents use smartphones and they have some level of awareness using them.

- An app can be developed to automate the existing process that the agents use. The app will give reports such as sales, money to be given to farmers and quantity of jasmine acquired over a period.

- From the personal interviews it is found that there is a willingness factor among the agents for an app that will assist them in their daily work with respect to Jasmine. 


\section{Data warehouse:}

Data warehouse will be a federated repository for all the data collected. Data such as user identification and credit data, is stored in the data warehouse database. User preferences and purchasing decisions, price information, trader information, farmer information will also be stored. Data warehouse will also include data collected from the Mobile application for agents and SMS Module. The data acquired by this function would be used for data analysis which will be helpful in marketing research and policy making.

\section{Data analysis:}

Data analysis function is one of the most important function as it not only helps in the improvisation of the framework, but it also gives valuable insights to various trends related to farming, trading etc. Using the data received from the data warehouse, data mining techniques can be applied to identify relationships, trends and other useful information. Information received from the analysis can be applied in decision making and marketing. Information can be also used to provide expert view on agricultural practices, e-commerce evolution etc. Data analysis will be beneficial in providing inputs to improve the framework over a period based.

\section{Policy Management:}

In India, agriculture is a highly regulated sector with government agencies and corporations exercising a persistent influence over it. Both central and state governments impose these regulatory controls. Information gained from data analysis can be used in government policy making. Policy making is a critical factor for the overall development of the grower. Agricultural support forms an essential part of farmer's income. Agricultural support ensures production and its development. In addition to aid, farmers may also receive structural support. Policy management will also improve agricultural productivity, develop the structure of agriculture and promote good agricultural practices. Based on the data analysis it can provide timely assistance to farmers incase of decrease in agricultural production.

\section{Benefits of the framework}

Agriculture, with its allied sectors, is the largest source of livelihoods in India. As per the report of Food and Agriculture Organization of the United Nations, 70 percent of India's rural households still depend primarily on agriculture for their livelihood, with 82 percent of farmers being small and marginal. This is true for the communitybased enterprise for Udupi jasmine growers. Therefore, the e-commerce framework will assist in integrating the rural and urban resources which will assist improving the socio-economic conditions of the growers involved in the jasmine production. In this process it will integrate information of both rural and urban market, provide guidance to market agricultural products.

Figure 2 explains the benefits of e-commerce framework. The farmer is given the maximum priority as he sits at the bottom of the pyramid. Farmers will have information about prices, best agriculture practices, government polices etc. E-commerce will integrate traders and consumers to provide an organized market. Traders will be assisted by the trading platform to conduct trade. Finally, the consumers will have a portal that will allow them to buy the product irrespective of their geographical location. As the market reach increases there will be an increase in demand

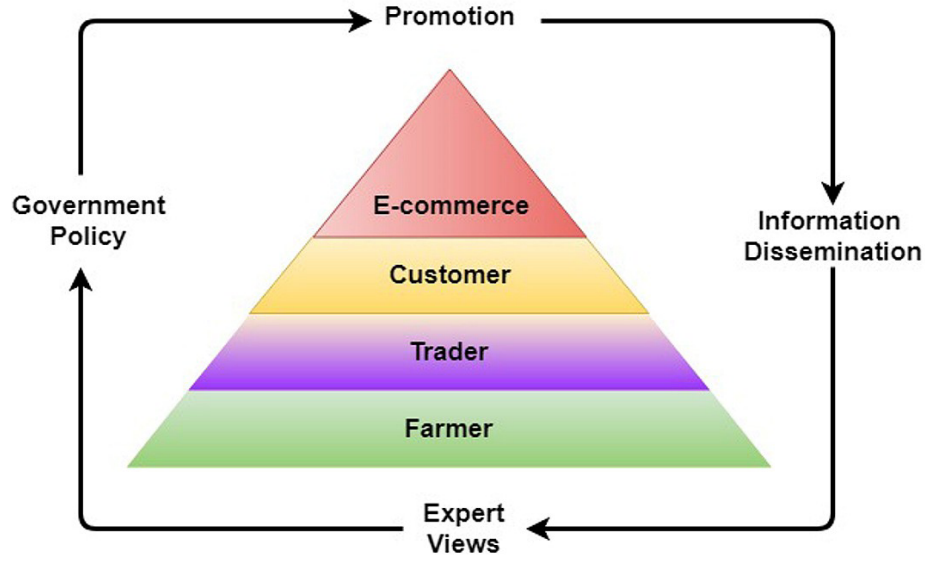

Source: own research and processing

Figure 2: E-commerce framework for Udupi Jasmine. 
which will directly affect the price of the product. Hence the farmer will benefit with the increase in demand. Effective information dissemination will be possible as the sector gets organized. As data will be integrated at all levels through the data warehouse it will allow experts provide inputs in various aspects of the supply chain that will assist in government policy making. Agriculture product promotion is a critical factor for e-agriculture to succeed. On promotion (Kotler and Keller, 2000) says that promotion is the element of market mix that includes all the ways a frim communicates the merits of its products and persuades its target customers to buy it. Hence product promotion will assist the product in reaching to a larger audience.

\section{Conclusion}

Marketing of agriculture products through internet has its own challenges due to several factors like shelf life, price, quantity, storage and location. In India there are many crops that are specific to a geographical location and Udupi jasmine is one among them. Existing e-commerce

framework cannot be used to market such crops

Corresponding authors

Darryl Jeethesh D'Souza

School of Information Sciences, Manipal Academy of Higher Education

Tiger Circle Road, Madhav Nagar, Manipal, Karnataka 576104, India

Email: darryl.j@manipal.edu

\section{References}

[1] Ashok, T. H. and Sarma, C. (2016) "Morphological and DNA marker-Based genetic diversity assessment and tagging QTLS controlling economic traits in jasmine (Jasminum spp.)", University of Agricultural Sciences, Bengaluru, pp. 68. [Online]. Available: http://shodhganga.inflibnet.ac.in/ handle/10603/6118 [Accessed: 15 Oct. 2018].

[2] Ballantyne, P. (2002) "Collecting and Propagating Local Development Content. Synthesis and Conclusions", International Institute for Communication and Development, Research, Report 7 (May). [Online]. Available: http://www.bibalex.org/search4dev/files/287987/ 118904.pdf [Accessed. 15 Dec. 2017].

[3] Chapman, R. and Slaymaker, T. (2002) "ICTs and Rural Development: Review of the Literature, Current Interventions, and Opportunities for Action", London: Overseas Development Institute, 31 p. ISBN 0-85003-619-4.

[4] Dong, M. (2016) "International comparisons on business model of agriculture e-commerce between India and China", International Conference on Industrial Economics System and Industrial Security Engineering (IEIS), pp. 1-5. ISBN 978-1-5090-1105-6. DOI 10.1109/IEIS.2016.7551881.

[5] Fruhling, A. L. and Digman, L. A. (2000) "The impact of electronic commerce on business-level strategies", Journal of Electronic Commerce Research, Vol. 1, No. 1, pp. 13-22. ISSN 1526-6133.

[6] Glendenning, C. and Ficarelli, P. (2012) "Content development and management processes of ICT initiatives in Indian agriculture", Information Development - INF DEV, Vol. 27, No. 4, pp. 301-314. ISSN 0266-6669. DOI 10.1177/0266666911425193. 
[7] Kotler, P. and Keller, L. K. (2000) “Marketing Management”, Pearson. ISBN 978-0-13-210292-6.

[8] Krishnamurthy, M. K., Parameshwar, N. S., Sridhar, H. P. and Mohan, E. (1995) "An analysis of farmers practice of Jasmine cultivation", Journal of the Indian Society of Coastal Agricultural Research, Vol. 13, No. 1, pp. 83-85. ISSN 0972-1584.

[9] Leroux, N., Wortman, S. and Mathias, D. (2001) "Dominant factors impacting the development of businessto-business (B2B) e-commerce in agriculture", International Food and Agribusiness Management Review, Vol. 4, No. 2, pp. 205-218. ISSN 1096-7508. DOI 10.1016/S1096-7508(01)00075-1.

[10] Markelova, H. R., Meinzen D. R., Hellin, J. and Dohrn, S. (2009) "Collective action for smallholder market access", Food Policy, Vol. 34, No. 1, pp. 7-14. ISSN 0306-9192. DOI 10.1016/j.foodpol.2008.10.001.

[11] Montealegre, F., Thompson, S. and Eales, J. S. (2007) "An Empirical Analysis of the Determinants of Success of Food and Agribusiness E-Commerce Firms", International Food and Agribusiness Management Review, Vol. 10, No. 1, pp. 61-81. ISSN 1096-7508.

[12] Silva, D. H. (2008) "Scoping Study: ICT and Rural Livelihoods South Asia Component", ICT for Rural Livelihoods Research Scoping Report, New Delhi: International Development Research Center, Oct 2008. [Online]. Available: http://www.bibalex.org/search4dev/ files/287987/ 118904.pdf [Accessed. 4 Feb. 2018].

[13] Treese, G. and Stewart, L. (2002) "Designing Systems for Internet Commerce, $2^{\text {nd }}$ edition, AddisonWesley Professional. ISBN 978-0-201-76035-4.

[14] Turban, E., King, D., Lee, J., and Warkentin, M. (2002) “Electronic Commerce 2002: A Managerial Perspective”, Prentice Hall, 914 p. ISBN 978-0-130-65301-7. 